\title{
Glucose regulation of guinea-pig sperm motility
}

\author{
A. Mújica ${ }^{1}$, R. Moreno-Rodríguez ${ }^{1}, J$ Naciff $^{1}$, L. Neri $^{1}$ and J. S. Tash ${ }^{2 *}$ \\ ${ }^{1}$ Departamento de Biología Celular, Centro de Investigación y de Estudios Avanzados del Instituto \\ Politécnico Nacional, Apdo. Postal 14740,07000 México, D. F. México; and ${ }^{2}$ Department of Cell \\ Biology, Baylor College of Medicine, Houston, TX 77096, USA
}

\begin{abstract}
Summary. Washed guinea-pig spermatozoa from the vas deferens re-acquired progressive motility within 1-2 min of incubation in minimal culture medium containing pyruvate and lactate. When glucose was added, either at the beginning or after $15 \mathrm{~min}$ of incubation, the cells showed stimulated motility (increased straight-line velocity, linearity and beat-cross frequency, $P<0.01$ ). Re-acquisition of progressive motility was preceded by a significant $(P<0.005)$ transient increase in sperm concentration of cyclic adenosine 5'-phosphate (cAMP) with or without glucose in the medium. Papaverine caused another large significant $(P<0.001)$ increase in cAMP concentration; and $5.56 \mathrm{~mm}$ glucose with papaverine caused a further stimulation in cAMP beyond that with papaverine alone $(P<0.005)$. Although 0.05 or $5.56 \mathrm{~mm}$ glucose plus $\alpha$-chlorohydrin stimulated sperm motility, they did not further stimulate the increase in cAMP after $30 \mathrm{~s}$ of incubation. Thus, there was no apparent correlation between the glucose-stimulating effect on sperm motility and the enhancement of cAMP at $30 \mathrm{~s}$. However, there was a close correlation between glucose-stimulated motility and enhancement of ATP $(P<0.05)$ by glucose even under incubation conditions in which glucose caused the Crabtree effect (decrease in respiration rate).
\end{abstract}

Keywords: spermatozoa; motility regulation; glucose; ATP; cAMP; a-chlorohydrin; guinea-pig

\section{Introduction}

ATP is the energy source for flagellar motion, the major energy-requiring process in spermatozoa (Mann \& Lutwak-Mann, 1981; Hammerstedt et al., 1988). Culture media usually contain glucose, lactate and pyruvate (Rogers, 1978), the metabolism of which provides the spermatozoa with energy for motility. Mammalian spermatozoa are unusual in showing a preference for glycolytic metabolism, even under aerobic conditions (Mann, 1964). Lardy \& Phillips (1941), showed that glucose decreased oxygen consumption in bull spermatozoa (Crabtree effect) and they suggested that glucose shifts sperm metabolism to the glycolytic pathway for part of the sperm energy. In guinea-pig spermatozoa, glucose also depresses respiration (Frenkel et al., 1973; Rogers et al., 1979; Coronel \& Lardy, 1987). Results from several species suggest that inclusion of a glycolysable substrate generally enhances fertilization; in fact, exogenous glucose is a requirement for rat, hamster and mouse sperm capacitation (reviewed by Fraser \& Ahuja, 1988). In contrast to the species in which glucose has a positive effect, guinea-pig spermatozoa incubated in pyruvate-lactate medium exhibits retarded acrosome reaction when glucose is present (Rogers \& Yanagimachi, 1975); it was suggested that glucose suppression of respiration retards the capacitation process and, therefore, the subsequent acrosome reaction (Rogers et al., 1979). Since guinea-pig spermatozoa incubated for $1 \mathrm{~h}$ in the presence of all three substrates, collected by centrifugation and resuspended in pyruvate-lactate medium, were able to undergo the acrosome reaction within $15 \mathrm{~min}$, Mújica \&

*Present address: Department of Physiology, University of Kansas Medical Center, Kansas City, KS 66201, USA. 
Valdes-Ruiz (1983) suggested that glucose does not retard capacitation per se. On the other hand, the delay of the acrosome reaction by glucose could be explained by glucose inhibition of calcium uptake in guinea-pig spermatozoa (Coronel \& Lardy, 1987). We have observed that, when guineapig spermatozoa are incubated in a chemically defined medium with lactate and pyruvate and are supplemented with glucose, the cells acquire higher motility and a different pattern of movement; but how does glucose activate sperm motility in conditions in which it is known to decrease sperm respiration rate?

There is substantial evidence for a role of cyclic adenosine 5 -phosphate (cAMP) (Garbers et al., 1971; Morton et al., 1974; Cascieri et al., 1976; Yijayaraghavan \& Hoskins, 1986; Niitsu-Hosoya et al., 1987; Morisawa \& Ishida, 1987), cAMP-dependent protein kinases and phosphorylation of specific proteins (Lindeman, 1978; Tash \& Means, 1983; Morisawa, 1985; Murofushi et al., 1986; Tash et al., 1986) in sperm motility initiation.

Many investigators have used inhibitors to augment cellular actions that involve pathways including cAMP (Vigdahl et al., 1971). Papaverine, like the methylxanthines, has been used frequently to inhibit cyclic nucleotide phosphodiesterase (Chasin \& Harris, 1976) and is one of the most potent inhibitors (O'Dea et al., 1970; Triner et al., 1970; Sheppard et al., 1972; Weiss, 1975), with effects upon adenosine uptake (Vigdahl et al., 1971) and glycogen breakdown (Triner et al., 1970). However, these metabolic pathways have not been demonstrated to occur in the guinea-pig spermatozoon.

An inhibitor of ATP synthesis, $\alpha$-chlorohydrin, has been well characterized for its effect on spermatozoa in a wide range of species (Ford \& Harrison, 1985, 1986, 1987), but its effect on ATP and motility of guinea-pig sperm has not yet been described.

Our interest in the cellular mechanism by which glucose stimulates sperm motility led us to evaluate concentrations of CAMP and ATP in guinea-pig sperm and their temporal correlation with motility.

\section{Materials and Methods}

Chemicals. Chemicals were purchased from the following sources: papaverine, dithiothreitol, EDTA, firefly lantern extract (3-( $N$-morpholino) propanesulphonic acid; Mops), ATP, $(R, S)$ - $\alpha$-chlorohydrin, polyvinylpyrrolidone (PVP, avg. $M_{\mathrm{r}} 40000$ from Sigma Chemical, Co., St Louis, MO, USA; sodium dodecyl sulphate (SDS), Triton X-100 from BDH Essex RM8 1QJ, UK; pentobarbitone sodium (Anestesal: Smith Kline Norden de Mexico, Mexico); Insta gel (Packard Instruments, Co., IL, USA); and dithionite from Merck, Darmstadt, Germany. All other chemicals were from J. T. Baker Chemical Co., Phillipsburg, NJ, USA.

Media. All media were prepared immediately.before use, from freshly distilled deionized water. The basic culture medium used was the minimal culture medium (MCM-PL; Barros, 1974) containing $102.3 \mathrm{~mm}-\mathrm{NaCl}, 1.71 \mathrm{mM}-\mathrm{CaCl}_{2}$, $25 \mathrm{~mm}-\mathrm{NaHCO}_{3}, 0.25 \mathrm{~mm}$ sodium pyruvate and $20 \mathrm{~mm}$ sodium lactate, $\mathrm{pH} 7.8$. When this medium was modified, the osmolality was maintained by adjusting the $\mathrm{NaCl}$ content. When 5.56 or $0.05 \mathrm{~mm}$ glucose, $5 \mu \mathrm{M}$ papaverine or $20 \mathrm{mM}$ $\alpha$-chlorohydrin (final concentrations) were added to the media, the $\mathrm{pH}$ was also adjusted to $7 \cdot 8$.

Sperm preparation and incubation. Spermatozoa from one guinea-pig or pooled from 2-4 animals and with good initial motility were used. Mature males $(700 \mathrm{~g}$ body weight) were anaesthetized with pentobarbitone sodium $(50 \mathrm{mg} / \mathrm{kg})$ and killed by cervical dislocation or $\mathrm{CO}_{2}$ asphyxiation. Testis-epididymis complexes were obtained and the spermatozoa were isolated by flushing the lumen of the vas deferens with $2 \mathrm{ml} 0.9 \%(\mathrm{w} / \mathrm{v}) \mathrm{NaCl}$ (saline) at $37^{\circ} \mathrm{C}$. The sperm suspension was centrifuged at $600 \mathrm{~g}$ for $4 \mathrm{~min}$ at room temperature. Pelleted spermatozoa were washed twice with half the original volume of saline, by dilution and centrifugation. Before the second centrifugation, an aliquant $(0.05 \mathrm{ml})$ was withdrawn to determine sperm concentration by haemocytometer count, as described by Mújica \& Valdes-Ruiz (1983). The remaining suspension was split into appropriate aliquots, transferred into glass test tubes $(10 \times 1.2 \mathrm{~cm})$ and centrifuged at room temperature for $4 \mathrm{~min}$ at $600 \mathrm{~g}$. The supernatant fluid was discarded (except $0.1 \mathrm{ml}$ from the bottom of the tube) using an automatic pipette. After washing, spermatozoa lacked progressive motility. Incubations were started by the addition of the desired prewarmed $\left(37^{\circ} \mathrm{C}\right)$ medium to washed, fluffy, pelleted spermatozoa. The final concentration in each medium was $35 \times 10^{6}$ spermatozoa $/ \mathrm{ml}$. The tubes were placed in a water bath at $37^{\circ} \mathrm{C}$ in air. Parallel incubations with and without the assayed compound(s) were run from the same washed sperm suspension.

Extraction of cAMP from sperm. At the desired time during incubation, $0.9-\mathrm{ml}$ samples were transferred to Eppendorf micro test-tubes and frozen in a solid $\mathrm{CO}_{2}$-acetone bath. To the frozen samples was added $0.1 \mathrm{ml} 200 \mathrm{~mm}$ 
Tris plus 40mm EDTA, pH 7.6. The sperm suspensions were thawed in boiling water. Five cycles of freezing and thawing were performed for cell membrane disruption (Hammerstedt et al., 1976) and no spermatozoa with intact acrosomes were observed. The cell suspensions were centrifuged at $12000 \mathrm{~g}$ in a microfuge for $10 \mathrm{~min}$ at room temperature. The supernatant $(0.9 \mathrm{ml})$ was lyophilized for cAMP evaluation and the pellet was saved for sperm determination by absorbance at $260 \mathrm{~nm}$. Recovery of cAMP was determined by addition of 8 pmol cAMP without a radioactive label, to parallel samples in which recovery of the added cAMP was $60 \%$.

Assay for cAMP. Immediately after dissolving the lyophilized sample in $0.2 \mathrm{ml}$ Tris-EDTA (20mM and $4 \mathrm{mM}$, respectively), cAMP was quantified by protein binding as outlined in the Amersham kits used (Amersham, Bucks, UK). The concentration of cAMP in the sample was obtained by interpolation on a standard curve, which was performed for each experiment (average correlation coefficient, $r=0.99$ ).

Extraction of sperm ATP. From the sperm incubations, $0 \cdot 2-\mathrm{ml}$ samples were removed and added to stoppered test tubes containing $0.8 \mathrm{ml}$ boiling water and held at that temperature for $10 \mathrm{~min}$ before transfer to an ice bath (Suter ct al. . 1979) and centrifuging at $5000 \mathrm{~g}$ for $30 \mathrm{~min}$ at $4^{\circ} \mathrm{C}$. The supernatant fluid $(0.8 \mathrm{ml})$ was withdrawn and stored at $-20^{\circ} \mathrm{C}$ for $20 \mathrm{~h}$ before determination of ATP. The pellet was saved for sperm re-evaluation at $260 \mathrm{~nm}$. Recovery of ATP was determined by addition of $50 \mathrm{pmol}$ cold ATP to parallel samples, in which recovery of the added ATP was $>95 \%$.

Measurement of ATP concentration. ATP was determined using the luciferase reaction (Wulff \& Döppen, 1985) adapted by M. B. Campos-Olalla in our laboratory. Briefly, for each experiment, $20 \mathrm{mg}$ buffered firefly lantern extract was reconstituted with $1.0 \mathrm{ml}$ water by mixing for $10 \mathrm{~min}$ (using a Vortex mixer) and centrifuged at $6000 \mathrm{~g}$ for $20 \mathrm{~min}$, and the clear pale yellow supernatant fraction was decanted into a glass tube; $0.03 \mathrm{ml}$ lantern extract was added to a vial containing $0.86 \mathrm{ml}$ of the buffer solution (50mM Mops, $10 \mathrm{~mm}-\mathrm{MgCl}_{2}, 5 \mathrm{~mm}-\mathrm{KH}_{2} \mathrm{PO}_{4}, \mathrm{pH} 7.8$ ) and mixed; the number of light flashes $/ 0.1 \mathrm{~min}$ was recorded (background), using a Lab-Line ATP-meter. Immediately, $0 \cdot 1 \mathrm{ml}$ sperm extract was added and swirled briskly and the number of light flashes $/ 0.1 \mathrm{~min}$ was recorded; the background value was subtracted. The time between enzyme or sample addition and the start of recording of light flashes was $5 \mathrm{~s}$. A standard curve was performed for each experiment (average correlation coefficient, $r=0.940 .99$ ). The ATP working range was $10-60 \mathrm{pmol} / \mathrm{vial}$. Distilled sterile water was used for diluting standard ATP or sperm extract when necessary.

Measurement of respiration rates. Respiration was measured in cell suspensions in a water-jacketed chamber at $37^{\circ} \mathrm{C}$, using a Clark-type Hansatech D.W. $\mathrm{O}_{2}$ electrode (Hansatech Limited; King's Lynn, Norfolk, UK). Spermatozoa were incubated in MCM-PL at $35 \times 10^{6} / \mathrm{ml}$, at $37^{\circ} \mathrm{C}$ in a water bath. At $12 \mathrm{~min}$ after starting the incubation, a $1-\mathrm{ml}$ sample was transferred to the oxymeter chamber and respiration rate was recorded. Once the steady-state was reached $(2-3 \mathrm{~min}), 5 \mu 1 \mathrm{MCM}-\mathrm{PL}$ plus $1 \cdot 112 \mathrm{M}$ glucose was added using a Hamilton syringe. Recording was stopped 2-3 min after the establishment of a linear respiratory rate. Then, $0.9 \mathrm{ml}$ was withdrawn and centrifuged and the sperm pellet was saved for sperm quantitation by absorbance at $260 \mathrm{~nm}$.

Sperm quantitation by absorbance at $260 \mathrm{~nm}$. Sperm cells were solubilized by the method of Hernández-Montes et al. (1973). The sperm pellets for which cAMP, ATP or oxygen uptake had been evaluated were treated with $0 \cdot 2 \mathrm{ml}$ $20 \mathrm{~mm}$ DTT plus $50 \mathrm{~mm}$ Tris, $\mathrm{pH} 9$, for $30 \mathrm{~min}$. Then $0.2 \mathrm{ml} 10 \% \mathrm{SDS}(\mathrm{w} / \mathrm{v})$ and $0.2 \mathrm{ml}$ distilled water were added; the samples were mixed using a Vortex mixer and sonicated (Branson Model B-12, microtip, setting 3) for $30 \mathrm{~s} ; 0.2 \mathrm{ml}$ aliquants of solubilized samples were diluted with $0.8 \mathrm{ml}$ phosphate-buffered saline $\left(5.68 \mathrm{~mm}-\mathrm{Na}_{2} \mathrm{HPO}_{4}, 132.44 \mathrm{~mm}\right.$ $\mathrm{NaCl}, \mathrm{pH} 7 \cdot 2$ ). The optical density was determined at $260 \mathrm{~nm}$, against a reagent blank. Numbers of sperm were read from a standard curve constructed with increasing sperm concentration, determined by 5 repeated haemocytometer counts for each dilution. Spermatozoa used for haemocytometer counts were suspended in $0.1 \%$ Triton X-100, to disperse aggregates, as described by Mújica \& Valdes-Ruiz (1983). The standard curve obtained showed a high correlation coefficient $(r=0.98)$.

Sperm treatment with $\alpha$-chlorahydrin. Spermatozoa were treated with $20 \mathrm{~mm} \alpha$-chlorohydrin at the start of incubation or were first washed in $\mathrm{NaCl}$ plus $\alpha$-chlorohydrin and incubated with $\alpha$-chlorohydrin (pretreated spermatozoa). For this, sperm cells from 3 guinea-pigs were obtained with $0.5 \mathrm{ml} 0.9 \% \mathrm{NaCl}$ solution per vas, pooled and split into two parts. One part ( $25 \%$ of the total volume) was added to an equal volume of saline and $40 \mathrm{~mm}$ $\alpha$-chlorohydrin and centrifuged. The sperm pellet was washed twice with saline plus $20 \mathrm{~mm} \alpha$-chlorohydrin $(1 \mathrm{ml}$ of the mixture/cells collected from one vas deferens) and then the cells were incubated in MCM-PL with glucose and $\alpha$ chlorohydrin. To the other part ( $75 \%$ of the initial sperm suspension) an equal volume of saline was added, centrifuged and washed twice without $\alpha$-chlorohydrin. Before centrifugation for the last wash, the suspension was split into three aliquots. Sperm pellets were incubated in MCM-PL, MCM-PL with glucose or MCM-PL with glucose and $\alpha$-chlorohydrin. Pretreatment with $\alpha$-chlorohydrin (in $\mathrm{NaCl}$ ) lasted 20 min.

Motility. Sperm motility was quantitated by computer-assisted digital image analysis using Cellsoft (CryoResources, Ltd, New York, NY, USA). Set-up parameters were modified from the method of Robertson et al. (1988): 30 frames analysed, 30 frames/s, minimum sampling for motility $=1$, minimum sampling for velocity $=13$, maximum instant velocity $=850 \mu \mathrm{m} / \mathrm{s}$ and threshold velocity $=25 \mu \mathrm{m} / \mathrm{s}$. For amplitude of lateral head displacement $(\mathrm{ALH})$ parameters; minimum number of points $=13$, minimum velocity $=25 \mu \mathrm{m} / \mathrm{s}$ and minimum linearity $=0$. Using a $\times 10 \mathrm{BM}$-phase objective on a Nikon Optiphot microscope with a $\times 1$ video adaptor, the $\mu \mathrm{m}$ :pixel ratio was $1 \cdot 136$. For recording, spermatozoa were diluted to a final concentration of $\sim 8-10 \times 10^{6}$ 
spermatozoa/ml in the appropriate incubation buffer containing 2\% (w/v) PVP; $8 \mu$ l of the suspension was placed in a slide chamber $32 \mu \mathrm{m}$ deep made from a $10-\mathrm{cm}$ plastic Petri dish (Falcon) and polished vinyl coverslips (Fisher 12 547). Chamber depth was determined by press-on letter Os from Chartpak (RDC 49). All transfer pipette tips and chamber surfaces were maintained at $37^{\circ} \mathrm{C}$. Recordings were made for $2-3 \mathrm{~min}\left(\right.$ at $37^{\circ} \mathrm{C}$ ), changing the field of view every $5 \mathrm{~s}$. Parameters measured in at least 200 spermatozoa were curvilinear (VCL) and straight-line (VSL) velocity, linearity $(\mathrm{LIN}=\mathrm{VSL} / \mathrm{VCL})$, mean lateral head amplitude (mean ALH), beat-cross frequency $(\mathrm{BCF}), \%$ circular paths (CIRC), and \% hyperactivated (HYPER).

Stastical analysis. The data were analysed using unpaired two-tailed Student's $t$ tests. Motility parameters were not normally distributed and so pairs of medians were compared by Kruskal-. Wallis one-way analysis of variance.

\section{Results}

Effect of glucose on motility of spermatozoa incubated in minimal culture medium with pyruvate and lactate

Washed spermatozoa without progressive motility re-acquired this movement by incubation in media with pyruvate and lactate with or without glucose.

The addition of $5.56 \mathrm{~mm}$ glucose increased the velocity of the cells and diminished the time needed for them to recover progressive motility. This was observed at 45 or $60 \mathrm{~s}$ after starting the incubation, which is $15-30$ s sooner than in spermatozoa incubated in pyruvate-lactate medium without glucose. VSL, BCF and LIN were significantly $(P<0.003)$ stimulated by glucose (Fig. 1). The proportion of HYPER spermatozoa increased with time of incubation in the absence of glucose, but their apparent decrease when glucose was added was not statistically significant. With $5.56 \mathrm{~mm}$ glucose, the effect on sperm motility lasted at least $1 \mathrm{~h}$, whereas with $0.05 \mathrm{~mm}$ glucose, the linear pattern of movement was maintained for up to $8 \mathrm{~min}$, but was lost by $15 \mathrm{~min}$.

\section{Effect of glucose on concentration of cAMP in spermatozoa}

Washed spermatozoa incubated in $0.9 \% \mathrm{NaCl}$ at $37^{\circ} \mathrm{C}$ for $30 \mathrm{~s}$ had a mean of $1.68 \pm 0.75 \mathrm{pmol}$ cAMP $/ 10^{7}$ spermatozoa $(n=10)$. A rapid and significant $(P<0.05)$ increase in cAMP concentration was observed after incubation for $30 \mathrm{~s}$ in MCM-PL with or without $5.56 \mathrm{~mm}$ glucose (Fig. 2), but the increase was greater with glucose. Although the increase in cAMP was always consistent and ranged from 34 to $79 \%$ in response to glucose, the mean value within treatment groups was not significantly higher than that in spermatozoa incubated without glucose. However, when the data were normalized to be a ratio between paired treatments, the standard deviation was a much smaller proportion of the overall ratio, suggesting that between-sample variation rather than treatment variation was the problem.

\section{Effect of glucose on concentration of cAMP in papaverine-treated spermatozoa}

To maximize any difference in intracellular cAMP concentration attributable to stimulation by glucose, incubations were carried out with papaverine (Triner et al., 1970; O'Dea et al., 1970), a phosphodiesterase inhibitor, to slow down the hydrolysis of cAMP (Table 1). Addition of $5 \mu \mathrm{M}$ papaverine to incubations in MCM-PL caused a dramatic increase in CAMP content to concentrations significantly $(P<0.001)$ higher than those in control spermatozoa, incubated for $30 \mathrm{~s}$ in MCM-PL without papaverine. Concentrations of cAMP in spermatozoa incubated in MCM-PL with $5.56 \mathrm{~mm}$ glucose and $5 \mu \mathrm{M}$ papaverine were significantly $(P<0.001)$ higher than those in MCM-PL with glucose, at $30 \mathrm{~s}$; and significantly $(P<0.005)$ higher than in spermatozoa in MCM-PL plus papaverine. On the other hand, in MCM-PL with papaverine with $0.05 \mathrm{~mm}$ glucose, cAMP concentration did not differ significantly from the value in the respective control without glucose. 


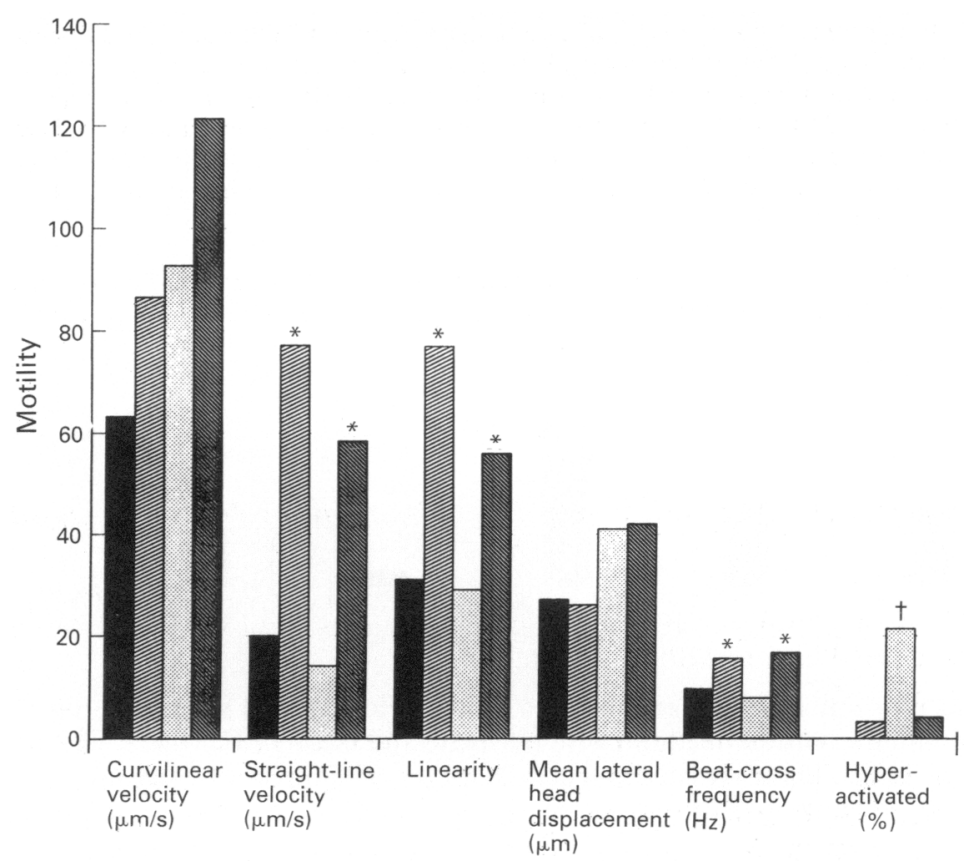

Fig. 1. Motility of guinea-pig spermatozoa incubated in minimal culture medium with pyruvate and lactate (MCM-PL) at 25 (ם) and 40 (回) min; and with $5.56 \mathrm{~mm}$ glucose in the medium for

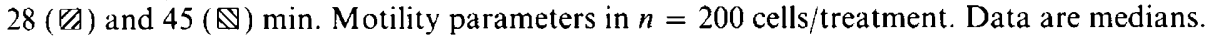

* Difference significant $(P<0.003)$ for MCM-PL plus glucose at $28 \mathrm{~min}$ vs. MCM-PL at $25 \mathrm{~min}$ for straight-line velocity, beat-cross frequency and linearity. Difference significant $(P<0.001)$ for MCM-PL plus glucose at $45 \mathrm{~min}$ vs. MCM-PL at $40 \mathrm{~min}$ for beat-cross frequency and hyperactivated and $(P<0.02)$ for linearity and straight-line velocity.

\section{Changes in concentration of cAMP by delayed addition of glucose}

At $15 \mathrm{~min}$ of incubation, cAMP was measured in spermatozoa on MCM-PL to establish the basal concentration. At the same time, $5.56 \mathrm{mM}$ glucose, $5 \mu \mathrm{M}$ papaverine, or both, in MCM-PL (volume addition was $5 \mu \mathrm{l} / \mathrm{ml}$ sperm suspension) was added to parallel sperm suspensions; cAMP was quantitated in samples withdrawn at 30 and $120 \mathrm{~s}$ (Fig. 3). At $30 \mathrm{sec}$ after addition, glucose plus papaverine caused a significant $(P<0.05)$ increase in cAMP concentration that was not maintained at the subsequent sampling. Neither glucose nor papaverine alone significantly increased cAMP concentration.

Sperm movement was changed markedly by the delayed addition of glucose (Fig. 1). Significant increases in all parameters of motility were observed (for BCF and HYPER, $P<0.001$; for LIN and VSL, $P<0.02$ ). However, papaverine in the presence or absence of glucose had no effect on motility (Fig. 4).

\section{Effect of glucose on ATP concentration}

Washed spermatozoa incubated in $0.9 \% \mathrm{NaCl}$ at $37^{\circ} \mathrm{C}$ for $30 \mathrm{~s}$ had a mean of $9.18 \pm 2.51 \mathrm{nmol}$ ATP $/ 10^{8}$ spermatozoa $(n=7)$. In MCM-PL, the ATP concentration remained at the basal level throughout incubation for $1 \mathrm{~min}$ (Table 2), but in MCM-PL supplemented with $0.05 \mathrm{~mm}$ glucose, intracellular ATP increased significantly $(P<0.025)$ at $30 \mathrm{~s}$ and remained significantly high $(P<0.05)$ after incubation for $1 \mathrm{~min}$. Addition of $5.56 \mathrm{~mm}$ glucose also significantly $(P<0.001)$ increased ATP concentration after incubation for $1 \mathrm{~min}$ (Table 2). 


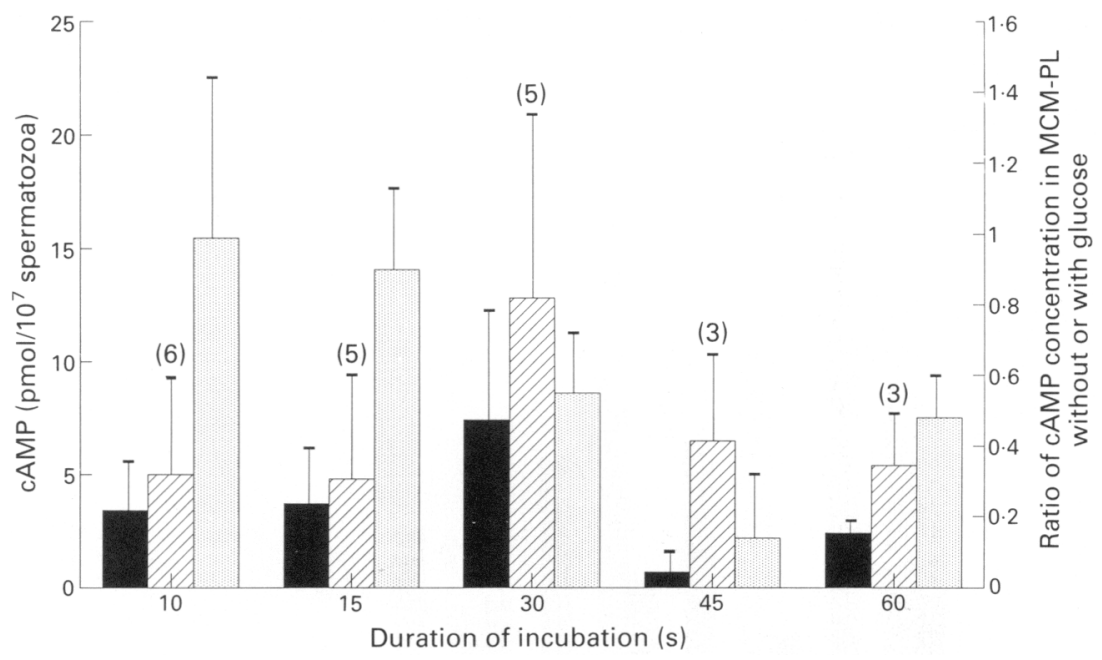

Fig. 2. Concentration of cyclic adenosine 5 -phosphate (cAMP) in guinea-pig spermatozoa incubated in minimal culture medium with pyruvate and lactate MCM-PL; $(\boldsymbol{\square})$ or with added $5.56 \mathrm{~mm}$ glucose $(\mathbb{Z})$. Data are means \pm s.d. Number of samples at each time is indicated in parentheses. To examine possible effects of sample variation, the ratio of cAMP in MCM-PL was divided by the paired value for MCM-PL with glucose in each replicate treatments and the mean of these ratios is also presented (圆).

Table 1. Effect of glucose concentration on concentration of cyclic adenosine 5 -phosphate (cAMP) at $30 \mathrm{~s}$ in guinea pig spermatozoa incubated* in minimal culture medium with pyruvate and lactate and treated with $5 \mu \mathrm{M}$ papaverine

\begin{tabular}{llc}
\hline Papaverine & $\begin{array}{c}\text { Glucose } \\
(\mathrm{mM})\end{array}$ & $\begin{array}{c}\text { cAMP } \\
\text { (pmo1/107 spermatozoa) }\end{array}$ \\
\hline- & 0 & $8.04 \pm 3.56$ \\
+ & 0 & $15 \cdot 58 \pm 3 \cdot 19^{\mathrm{a}}$ \\
+ & 0.05 & $13.13 \pm 3.81$ \\
- & 0 & $7.81 \pm 1.48$ \\
- & 5.56 & $9.07 \pm 1.78$ \\
+ & 0 & $20.60 \pm 0.64^{\mathrm{b}}$ \\
+ & 5.56 & $35.60 \pm 3.67^{\mathrm{dd}}$ \\
\hline
\end{tabular}

*At $35 \times 10^{6}$ spermatozoa $/ \mathrm{ml}$ at $37^{\circ} \mathrm{C}$.

Data are means \pm s.d.; $n=3$ and $n=4$ for experiments with 5.56 and $0.05 \mathrm{~mm}$ glucose, respectively.

${ }^{a} P<0.02$ (with vs. without papaverine).

${ }^{\mathrm{b}} P<0.001$ (with vs. without papaverine).

${ }^{c} P<0.001$ (with glucose and papaverine vs. with glucose).

${ }^{\mathrm{d}} P<0.005$ (with glucose and papaverine vs. with papaverine).

Addition of $5.56 \mathrm{~mm}$ glucose to spermatozoa after incubation for $15 \mathrm{~min}$ in MCM-PL increased ATP concentration to values significantly $(P<0.05)$ higher than its respective control. In cells with $18 \cdot 20 \pm 3 \cdot 15 \mathrm{nmol}$ ATP $/ 10^{8}$ spermatozoa $1 \mathrm{~min}$ after addition of glucose (or PL control), values were $16 \cdot 50 \pm 2 \cdot 90$, in MCM-PL and $30 \cdot 82 \pm 8 \cdot 35$ in MCM-PL with glucose. 


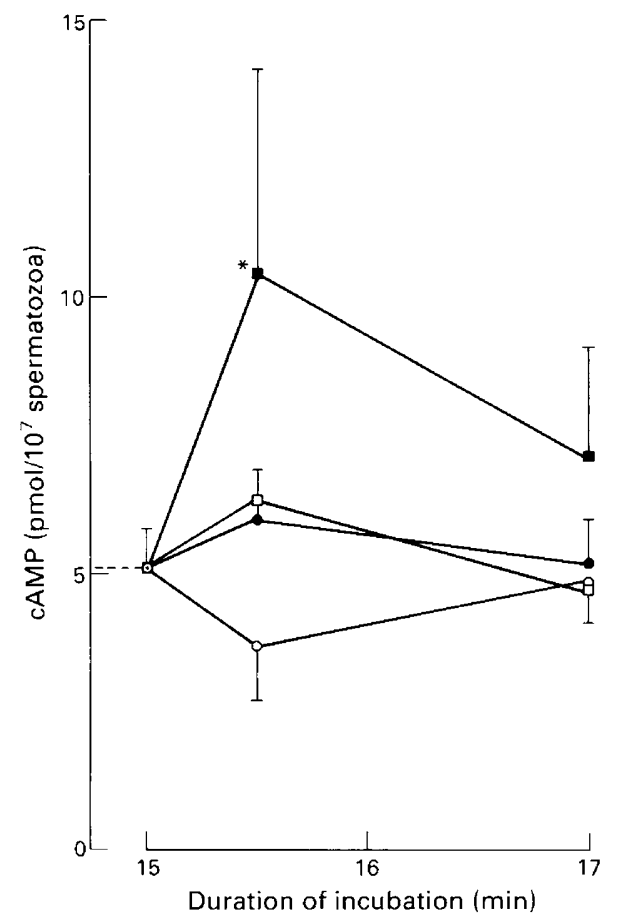

Fig. 3. Concentration of cyclic adenosine 5'-phosphate (cAMP) in guinea-pig spermatozoa $\left(35 \times 10^{6}\right.$ cells $\left./ \mathrm{ml}\right)$ incubated in minimal culture medium with pyruvate and lactate $(O)$ for $15 \mathrm{~min}$ before addition of $5 \mu \mathrm{M}$ papaverine $(\bullet)$ or $5.56 \mathrm{~mm}$ glucose $(\square)$ or both $(\boldsymbol{\square})$. Data are means \pm s.d. $(n=4)$. *Significantly different from basal value (cAMP concentration in spermatozoa incubated for $15 \mathrm{~min}$ ).

\section{Effect of glucose on sperm respiration rate}

The enhancement of ATP concentration by glucose was unexpected, because it has been reported (Coronel \& Lardy, 1987) that glucose decreases the respiratory rate of guinea-pig spermatozoa incubated with pyruvate and lactate.

We measured the effect of $5.56 \mathrm{~mm}$ glucose, added $15 \mathrm{~min}$ after incubation was initiated in MCM-PL. The oxygen consumption was $14.42 \pm 3.3$ and $8.76 \pm 2.4 \mathrm{nmol} / 10^{8}$ cells per min $(n=6)$ in MCM-PL before and after the addition of glucose, respectively. Our values were higher than those reported by Coronel \& Lardy (1987) who used similar incubation conditions but a higher sperm concentration, which could have affected respiration as has been shown in other mammalian spermatozoa (Deutch et al., 1985). On the other hand, in agreement with the results of Coronel \& Lardy (1987) a mean inhibition of oxygen consumption of $39 \cdot 25 \%$ was observed after addition of glucose.

\section{Effect of inhibition of glycolysis by $(R, S)$ - $\alpha$-chlorohydrin on sperm motility}

Addition of $20 \mathrm{~mm} \alpha$-chlorohydrin to spermatozoa incubated in MCM-PL plus $5 \cdot 56 \mathrm{~mm}$ glucose did not inhibit the stimulation of sperm motility by glucose up to $10 \mathrm{~min}$ of incubation. Thereafter, the effect of the $\alpha$-chlorohydrin began to be apparent; by $20 \mathrm{~min}$ all parameters of motility (except BCF) were no longer significantly different from those for spermatozoa incubated without glucose (data not shown).

When spermatozoa were treated with $\alpha$-chlorohydrin during washing and then incubated in MCM-PL with glucose and $\alpha$-chlorohydrin, the cells showed a reduced rate of flagellar beat with increased bending similar to that observed in spermatozoa incubated in MCM-PL without glucose. 


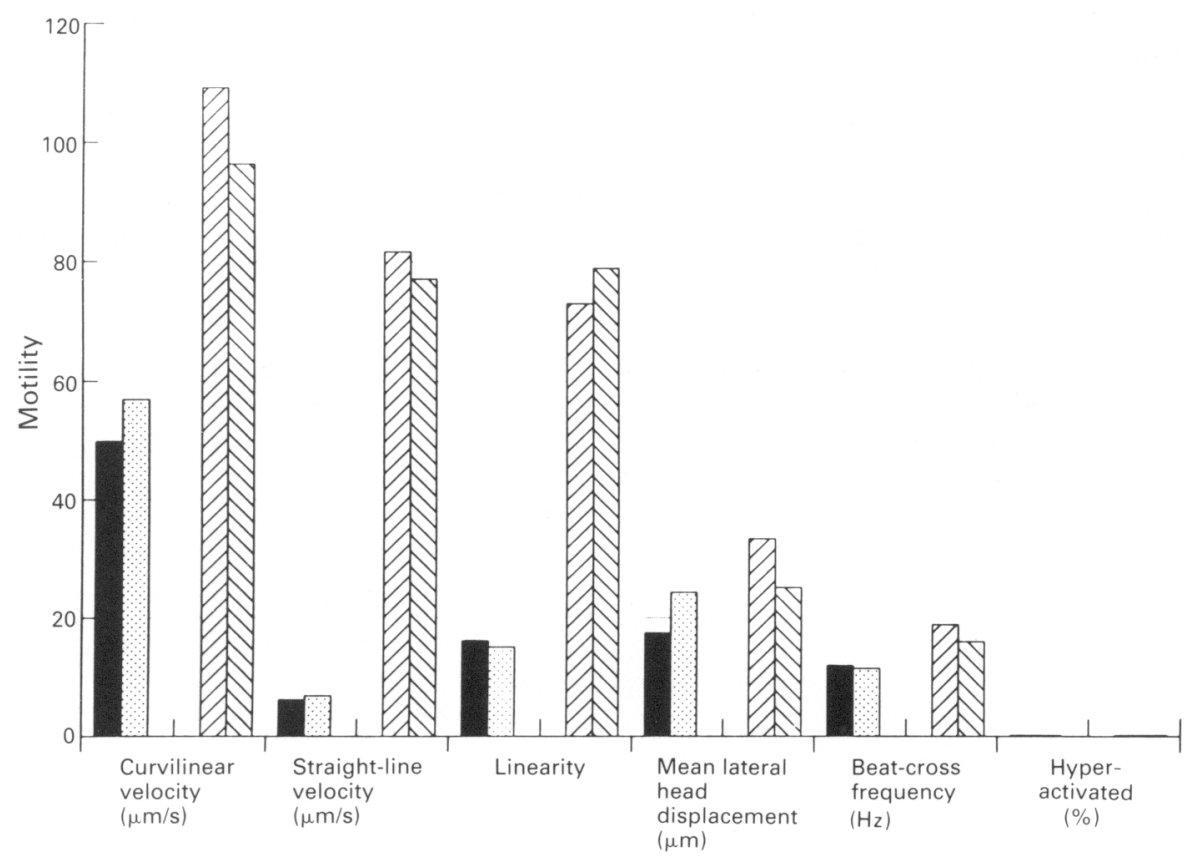

Fig. 4. Motility of guinea-pig spermatozoa incubated in minimal culture medium with (i) pyruvate and lactate ( $)$ or (ii) pyruvate, lactate and glucose $(E)$ for $15-25 \mathrm{~min}$ before addition of $5 \mu \mathrm{M}$ papaverine to (i) $\left(\right.$ : $:$ ) , or to (ii) $(\mathbb{\mathbb { N }})$. ${ }^{*}$ There was a small but significant effect $(P<0.05)$ of papaverine on beat-cross frequency in the samples with glucose.

Table 2. Effect of glucose concentration on ATP concentration in guinea-pig spermatozoa incu-

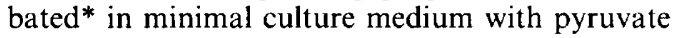
and lactate

\begin{tabular}{|c|c|c|}
\hline \multirow{2}{*}{$\begin{array}{l}\text { Time of } \\
\text { incubation } \\
\text { (s) }\end{array}$} & \multicolumn{2}{|c|}{ ATP (nmol/ $10^{8}$ spermatozoa) } \\
\hline & $\begin{array}{l}\text { Without } \\
\text { glucose }\end{array}$ & $\begin{array}{c}\text { With } \\
\text { glucose }\end{array}$ \\
\hline & & $0.05 \mathrm{~mm}$ glucose \\
\hline 10 & $9 \cdot 10 \pm 6 \cdot 80$ & $12 \cdot 00 \pm 4 \cdot 30$ \\
\hline 30 & $10 \cdot 38 \pm 6 \cdot 10$ & $23.83 \pm 2.56^{\mathrm{a}}$ \\
\hline 60 & $10 \cdot 46 \pm 5.62$ & $\begin{array}{l}24.99 \pm 6.52^{\mathrm{b}} \\
5.56 \mathrm{mM} \text { glucose }\end{array}$ \\
\hline 10 & $9 \cdot 36+4 \cdot 59$ & $7 \cdot 79+5 \cdot 73$ \\
\hline 30 & $9.26 \pm 4.12$ & $11.43 \pm 5.50$ \\
\hline 60 & $8.78 \pm 3.38$ & $21.71 \pm 4.08^{c}$ \\
\hline
\end{tabular}

*At $35 \times 10^{6}$ spermatozoa $/ \mathrm{ml}$ at $37^{\circ} \mathrm{C}$.

Data are means \pm s.d.; $n=5$ and $n=3$ for experiments with 5.56 and $0.05 \mathrm{~mm}$ glucose, respectively.

${ }^{a} P<0.025$; ${ }^{\mathrm{b}} P<0.05$; $\mathrm{c} P<0.001$ compared with respective control.

However, the prolonged exposure to $\alpha$-chlorohydrin also rendered the spermatozoa extremely sticky, preventing progressive movement in the motility analysis chamber. Other parameters of movement could, therefore, not be quantified. 
Effect of glucose plus $(R, S)$ - $\alpha$-chlorohydrin on cAMP concentrations in papaverine-treated spermatozoa

Glucose did not increase sperm cAMP at 30 s (Table 3) when spermatozoa washed in $\mathrm{NaCl}$ or in $\mathrm{NaCl}$ plus $\alpha$-chlorohydrin were incubated in MCM-PL with papaverine, $5.56 \mathrm{~mm}$ glucose and $\alpha$-chlorohydrin. Concentration of cAMP in both was similar to that in spermatozoa in MCM-PL plus papaverine without glucose and significantly $(P<0.025)$ lower in MCM-PL with glucose and papaverine.

Table 3. Effects of $5.56 \mathrm{~mm}$ glucose and $20 \mathrm{~mm}(\mathrm{R}, \mathrm{S})-\alpha$-chlorohydrin on concentration of cyclic adenosine $5^{\prime}$-phosphate (cAMP) at $30 \mathrm{~s}$ in guinea-pig spermatozoa incubated* in minimal culture medium with pyruvate and lactate and treated with $5 \mu \mathrm{M}$ papaverine

\begin{tabular}{llc}
\hline Glucose & $\begin{array}{c}\text { Timing of treatment } \\
\text { with } \alpha \text {-chlorohydrin }\end{array}$ & $\begin{array}{c}\text { cAMP } \\
\text { (pmol/107 spermatozoa) }\end{array}$ \\
\hline (Control) & - & $16.02 \pm 3 \cdot 13^{\mathrm{a}}$ \\
+ & - & $25.48 \pm 3.08^{\mathrm{b}}$ \\
+ & $\begin{array}{l}\text { From start of } \\
\text { incubation }\end{array}$ & $13.24 \pm 5 \cdot 15^{\mathrm{c}}$ \\
+ & $\begin{array}{l}\text { During washings } \\
\text { and incubation }\end{array}$ & $13.73 \pm 5.91^{\mathrm{c}}$ \\
\hline
\end{tabular}

*At $35 \times 10^{6}$ washed spermatozoa $/ \mathrm{ml}$ at $37^{\circ} \mathrm{C}$.

Data are means \pm s.d. $(n=3)$.

$P<0.02$ (b vs. a).

$P<0.025$ (c vs. b).

\section{Effect of $(R, S)$ - $\alpha$-chlorohydrin on sperm ATP concentration}

In spermatozoa incubated in MCM-PL a statistically significant $(P<0.05)$ increase in ATP occurred between 1 and $5 \mathrm{~min}$ of incubation. Then, slowly declining, ATP concentration at 10 and 19 min were slightly, but not significantly, lower than the value at $5 \mathrm{~min}$ (Table 4).

Table 4. Effects of $5.56 \mathrm{~mm}$ glucose and $20 \mathrm{~mm}(R, S)-\alpha$-chlorohydrin on ATP concentration in guinea-pig spermatozoa incubated* in minimal culture medium with pyruvate and lactate

\begin{tabular}{|c|c|c|c|c|c|}
\hline \multirow[b]{3}{*}{ Glucose } & \multirow{3}{*}{$\begin{array}{l}\text { Timing of treatment } \\
\text { with } \alpha \text {-chlorohydrin }\end{array}$} & \multicolumn{4}{|c|}{$\operatorname{ATP}\left(\mathrm{nmol} / 10^{8}\right.$ spermatozoa $)$} \\
\hline & & \multicolumn{4}{|c|}{ Incubation time (min) } \\
\hline & & 1 & 5 & 10 & 19 \\
\hline$-($ Control $)$ & - & $12.69 \pm 1.49$ & $18 \cdot 73 \pm 4 \cdot 7$ & $17 \cdot 37 \pm 3.74$ & $14 \cdot 36 \pm 1 \cdot 16$ \\
\hline+ & - & $28.07 \pm 5.90^{\mathrm{a}}$ & $27 \cdot 34 \pm 2 \cdot 60^{\mathrm{a}}$ & $34.64 \pm 4.42^{\mathrm{a}}$ & $30 \cdot 10 \pm 7 \cdot 51^{\mathrm{a}}$ \\
\hline+ & $\begin{array}{l}\text { From start of } \\
\text { incubation }\end{array}$ & $31.06 \pm 9.02$ & $25 \cdot 56 \pm 1 \cdot 80$ & $19 \cdot 41 \pm 4 \cdot 26^{\mathrm{b}}$ & $11 \cdot 22 \pm 1 \cdot 16^{b}$ \\
\hline+ & $\begin{array}{l}\text { During washings } \\
\text { and incubation }\end{array}$ & $17 \cdot 27 \pm 4 \cdot 76^{c}$ & $12 \cdot 25 \pm 5 \cdot 20^{c}$ & $5 \cdot 74 \pm 1 \cdot 15^{\circ}$ & $5 \cdot 80 \pm 1 \cdot 50^{c}$ \\
\hline
\end{tabular}

*At $35 \times 10^{6}$ spermatozoa $/ \mathrm{ml}$ at $37^{\circ} \mathrm{C}$.

Data are means \pm s.d. $(n=4)$.

${ }^{a} P<0.01$ compared with its respective control without glucose.

${ }^{b} P<0.05$ vs. ATP in spermatozoa incubated for $5 \mathrm{~min}$ in the same medium.

${ }^{c} P<0.01$ compared with its respective control without $\alpha$-chlorohydrin. 
Addition of $5.56 \mathrm{~mm}$ glucose to spermatozoa incubated in MCM-PL dramatically increased ATP concentration to values significantly $(P<0.01)$ higher than those in MCM-PL without glucose for 1-19 min incubation (Table 4).

Addition of $20 \mathrm{~mm} \alpha$-chlorohydrin to the incubations in MCM-PL with glucose did not inhibit the enhancement of ATP concentration by glucose over the first 5 min of incubation. After that, a progressive decrease in ATP concentration was observed, values at 10 and 19 min being significantly $(P<0.05)$ lower than in spermatozoa at 5 min of incubation.

When spermatozoa washed in $\mathrm{NaCl}$ plus $\alpha$-chlorohydrin were incubated in MCM-PL with $5.56 \mathrm{~mm}$ glucose and $\alpha$-chlorohydrin, glucose-enhancement of ATP concentration was inhibited (Table 4). At I min of incubation, ATP concentration was slightly, but not significantly, higher than in spermatozoa incubated in glucose-free MCM-PL, but lower $(P<0.05)$ than in the control without $\alpha$-chlorohydrin. As incubation proceeded, the ATP concentration declined and, from 5 to $19 \mathrm{~min}$ of incubation, ATP values were significantly $(P<0.01)$ lower than in the respective controls without $\alpha$-chlorohydrin treatment and even lower than in spermatozoa incubated in MCM-PL.

\section{Discussion}

In our studies, re-acquisition of progressive sperm motility was preceded by transient increase in cAMP at $30 \mathrm{~s}$ of incubation in the media with or without glucose. This is similar to previous observations for de-novo motility initiation in spermatozoa from a range of mammalian and other species (Morton et al., 1974; Cascieri et al., 1976; Niitsu-Hosoya et al., 1987; Morisawa \& Ishida, 1987). The temporal relationship between cAMP and motility interaction was demonstrated by Morisawa \& Ishida (1987) who found that the activity of adenylate cyclase and cAMP concentrations increased and reached maximum values within seconds before onset of flagellar activity. Subsequently (within seconds), the activity of phosphodiesterase increased. In our results, the re-acquired progressive motility, the vigour and the pattern of movement were dependent on the metabolic substrate mixture used. In pyruvate-lactate medium, the cells adopted a less linear pattern of movement, with low beat frequency. When glucose was added, a striking change was observed, the cells exhibiting an increased beat frequency and higher linearity and amplitude of head displacement along the trajectory.

The results show a close correlation between activation of motility and enhanced ATP concentration by glucose. With 0.05 or $5.56 \mathrm{~mm}$ glucose, ATP concentration increased significantly ( $P<0.05$ and $P<0.001$, respectively) (Table 2$)$. Even under incubation conditions in which the glucose Crabtree effect was apparent, the carbohydrate caused a significant $(P<0.05)$ increase in sperm ATP concentration. Furthermore, when incubated with $(R, S)$ - $\alpha$-chlorohydrin, sperm motility remained activated by the glucose, until ATP concentration diminished to the value in spermatozoa incubated in glucose-free, pyruvate-lactate medium. The glucose-enhancing effect on ATP concentration in guinea-pig spermatozoa incubated with pyruvate-lactate seems to be species-characteristic, since ATP concentration in ram spermatozoa incubated with pyruvate-lactate, did not change with or without glucose, (Ford \& Harrison, 1985).

A high rate of aerobic glycolysis occurs in guinea-pig spermatozoa obtained from the vas deferens $\left(\mathrm{V}_{\max }=0.6 \mu \mathrm{mol} / 10^{8}\right.$ spermatozoa per $\left.\mathrm{h}\right)$ Frenkel et al., 1973). This rate is higher than that observed by Ford \& Harrison (1987) in boar and rat spermatozoa $\left(0.04\right.$ and $0.15 \mu \mathrm{mol} / 10^{8}$ spermatozoa per $h$, respectively). Pyruvate plus lactate decrease glucose metabolism in boar spermatozoa (Ford \& Harrison, 1987). From our results, the sperm motility characteristics elicited by $0.05 \mathrm{~mm}$ glucose in spermatozoa incubated in MCM-PL lasted up to $15 \mathrm{~min}$, and then consumption was $0.571 \mu \mathrm{mol}$ glucose $/ 10^{8}$ spermatozoa per $\mathrm{h}$.

Hiipakka \& Hammerstedt (1978) have shown that glucose transport depends upon its exogenous concentration. Our data showing an earlier increase in ATP concentration with $0.05 \mathrm{~mm}$ glucose than with $5.56 \mathrm{~mm}$ glucose (Table 2) are in agreement with the suggestion that a higher rate 
of glucose consumption occurs with higher glucose concentration. A higher rate of glucose uptake corresponds with more rapid ATP consumption for hexose phosphorylation by hexokinase. Based on the above considerations with the low $0.05 \mathrm{~mm}$ glucose concentration, the initial hexose uptake might be higher than the mean glucose consumption calculated $\left(0.571 \mu \mathrm{mol} / 10^{8}\right.$ spermatozoa per h) and could explain the observed increase in ATP concentration.

Flux through the sperm Embden-Meyerhof pathway can be varied by addition of metabolic effectors such as caffeine (Lardy \& Phillips, 1941; Garbers et al., 1973a, b), exogenous cAMP or cAMP analogues (Hoskins et al., 1971). A transient rise in cAMP might alter glycolytic rates considerably. However, the increase in ATP concentration caused by glucose without a further increase in cAMP might indicate that an upper limit of cAMP formation coupled to glycolysis may have already been reached.

If cAMP concentrations are already saturating for its target enzymes (cAMP-dependent protein kinase), no effect of additional increases in cAMP on motility would be expected, provided that there is sufficient ATP for motility and/or phosphorylation. This is supported by the observation that motility achieved with $0.05 \mathrm{~mm}$ glucose was indistinguishable from that with $5.56 \mathrm{~mm}$ glucose with or without $\alpha$-chlorohydrin, in spite of widely different concentrations of cAMP under these conditions (Tables $I$ and 3, respectively). At low glucose concentrations, one might conclude that ATP, rather than CAMP, is rate-limiting, since a low concentration of glucose stimulates motility, but without a measurable increase in cAMP. Similarly, in the absence of glucose, papaverine stimulated the production of cAMP (Table 1) without producing a change in motility (Fig. 4).

A high concentration $(20 \mathrm{~mm})$ of $(R, S)$ - $\alpha$-chlorohydrin was required to affect, within a short incubation period $(10 \mathrm{~min})$, the motility of guinea-pig spermatozoa elicited by $5.56 \mathrm{~mm}$ glucose, when the cells were incubated in pyruvate-lactate medium. Lower doses of $\alpha$-chlorohydrin (1.0mm) altered motility in ram spermatozoa incubated with pyruvate-lactate-glucose (Ford \& Harrison, 1985). This may be a reflection of the rate of production of the inhibitory metabolite (3-chloroacetaldehyde) in situ (Jones \& Ford, 1984). In guinea-pig spermatozoa, the earliest $\alpha$ chlorohydrin effect was inhibition of the further cAMP increase produced by $5.56 \mathrm{~mm}$ glucose with pyruvate and lactate (Table 3). A concerted effect of $\alpha$-chlorohydrin and glucose to produce a decline in sperm ATP concentration has been established (Ford \& Harrison, 1986). Also, pyruvate plus lactate protects the spermatozoa of some species from the glucose- $\alpha$-chlorohydrin effect on ATP (Ford \& Harrison, 1985). In our experiments pyruvate plus lactate did not inhibit the ATP decline in guinea-pig spermatozoa incubated with $\alpha$-chlorohydrin plus glucose (Table 4 ). This is in accord with observations in ram spermatozoa, but in contrast to those in boar spermatozoa (Ford \& Harrison, 1986).

The inclusion of glucose in the pyruvate-lactate medium confers on guinea-pig spermatozoa higher progression and a more linear pattern of movement. The secretion of glucose by seminal vesicles in guinea-pig was communicated by Fouquet (1971), and the presence of pyruvate and lactate in the seminal plasma by Mann \& Lutwat-Mann (1981). All these observations suggest a physiological role for glucose.

We thank Dr A. Huberman, Dr F. Posadas del Río, Dr S. Villa-Treviño and Dr D. López for helpful comments on the manuscript; M. en C. M. B. Campos-Olalla for valuable advice on ATP and $\mathrm{O}_{2}$ techniques; and $\mathrm{Dr} M$. Tuena for the loan of equipment. This research was partly supported by Consejo Nacional de Ciencia y Tecnología, grant PCSABNA-022046 and by Consejo del Sistema Nacional de Educación Tecnológica, grant 769,87.

\section{References}

Barros, C. (1974) Capacitation of mammalian spermatozoa. In Physiology and Genetics of Reproduction, part
B, pp. 3-24. Eds E. M. Countinho \& F. Fuchs. Plenum Press, New York. 
Cascieri, M., Amann, R.P. \& Hammerstedt, R.H. (1976) Adenine nucleotide changes at initiation of bull sperm motility. J. biol. Chem. 251, 787-793.

Chasin, M. \& Harris, D.N. (1976) Inhibitors and activators of cyclic nucleotide phosphodiesterase. $A d v$. Cyclic Nucleotide Res. 7, 225-264.

Coronel, C.E. \& Lardy, H.A. (1987) Characterization of $\mathrm{Ca}^{2+}$ uptake by guinea pig epididymal spermatozoa. Biol. Reprod. 37, 1097-1107.

Deutch, D.S., Katz, D.F. \& Overstreet, J.W. (1985) Increases in human sperm oxygen consumption at low cell concentrations. Biol. Reprod. 32, 865-871.

Ford, W.C.L. \& Harrison, A. (1985) The presence of glucose increases the lethal effect of $\alpha$-chlorohydrin in ram and boar spermatozoa in vitro. J. Reprod. Fert. 73, 197-206.

Ford, W.C.L. \& Harrison, A. (1986) The concerted effect of $\alpha$-chlorohydrin and glucose on the ATP concentration in spermatozoa is associated with the accumulation of glycolytic intermediates. J. Reprod. Fert. 77, $537-545$

Ford, W.C.L. \& Harrison, A. (1987) Futile substrate cycles in the glycolytic pathway of boar and rat spermatozoa and the effect of $\alpha$-chlorohydrin. $J$. Reprod. Fert. 79, 21-32.

Fouquet, J.P. (1971) Secretion of free glucose and related carbohydrates in the male accessory organs of rodents. Comp. Biochem. Physiol.40A, 305-317.

Fraser, L.R. \& Ahuja, K.K. (1988) Metabolic and surface events in fertilization. Gamete Res. 20,491-519.

Frenkel, G., Peterson, R.N. \& Freund, M. (1973) Changes in the metabolism of guinea pig sperm from different segments of the epididymis. Proc. Soc. exp. Biol. Med. 143, 1231-1236.

Garbers, D.L., Lust, W.D., First, N.L. \& Lardy, H.A. (1971) Effects of phosphodiesterase inhibitors and cyclic nucleotides on sperm respiration and motility. Biochemistry, N.Y.10,1825-1831

Garbers, D.L., First, N.L. \& Lardy, H.A. (1973a) The stimulation of bovine epidydimal sperm metabolism by cyclic nucleotide phosphodiesterase inhibitors. Biol. Reprod. 8, 589-598.

Garbers, D.L., First, N.L., Gorman, S.K. \& Lardy, H.A. (1973b) The effects of cyclic nucleotide phosphodiesterase inhibitors on ejaculated porcine spermatozoan metabolism. Biol. Reprod. 8, 599-606.

Hammerstedt, R.H., Amann, R.P., Rucinsky, T., Morse II, P.D., Lepock, J., Snipes, W. \& Keith, A.D. (1976) Use of spin labels and electron spin resonance spectroscopy to characterize membranes of bovine sperm: effect of butylated hydroxytoluene and cold shock. Biol. Reprod. 14, 381-397.

Hammerstedt, R.H., Volonté, C. \& Racker, E. (1988) Motility, heat, and lactate production in ejaculated bovine sperm. Arch. Biochem. Biophys. 266, 111-123.

Hernández-Montes, H., Iglesias, G. \& Mújica, A. (1973) Selective solubilization of mammalian spermatozoa structures. Expl Cell Res. 76, 437-440.

Hiipakka, R.A. \& Hammerstedt, R.H. (1978) 2Deoxyglucose transport and phosphorylation by bovine sperm. Biol. Reprod. 19, 368-379.

Hoskins, D.D., Stephens, D.T. \& Casillas, E.R. (1971) Enzymic control of fructolysis in primate spermatozoa. Biochim. Biophys. Acta 237, 227-238.
Jones, A.R. \& Ford, S.A. (1984) The action of (S)- $\alpha$ chlorohydrin and 6-chloro-6-deoxyglucose on the metabolism of guinea pig spermatozoa. Contraception 30, 26l-269.

Lardy, H.A. \& Phillips, P.H. (1941) The interrelation of oxidative and glycolytic processes as sources of energy for bull spermatozoa. Am. J. Phisiol. 133, 602-609.

Lindeman, C.B. (1978) A cAMP-induced increase in the motility of demembranated bull sperm models. Cell 13, $9-18$.

Mann, T. (1964) Fructose, polyols, and organic acids. In The Biochemistry of Semen and the Male Reproductive Tract, pp. 237-264. John Wiley and Sons, Inc., New York.

Mann, T. \& Lutwak-Mann, C. (1981) Biochemistry of spermatozoa: chemical and functional correlations in ejaculated semen. Andrological aspects. In Male Reproductive Function and Semen, pp. 195-268. Springer-Verlag, Berlin.

Morisawa, M. (1985) Initiation mechanism of sperm motility at spawning in teleosts. Zool. Sci. 2, 605-615.

Morisawa, M. \& Ishida, K. (1987) Short-term changes in levels of cyclic AMP, adenylate cyclase, and phosphodiesterase during the initiation of sperm motility in rainbow trout. J. exp. Zool. 242, 199-204.

Morton, B., Harrigan-Lum, I., Albagli, L. \& Jooss, T. (1974) The activation of motility in quiescent hamster sperm from the epididymis by calcium and cyclic nucleotides. Biochem. Biophys. Res. Commun. 56, 372-379.

Mújica, A. \& Valdes-Ruiz, M.A. (1983) On the role of glucose in capacitation and acrosomal reaction of guinea pig sperm. Gamete Res. 8, 335-344.

Murofushi, H., Ishiguro, K., Takahashi, D., Ikeda, J. \& Sakai, H. (1986) Regulation of sperm flagellar movement by protein phosphorylation and dephosphorylation. Cell Motil. Cytoskeleton 6, 83-88.

Niitsu-Hosoya, N., Ishida, K. \& Mohri, H. (1987) Changes in intracellular concentrations of cyclic nucleotides during the initiation process of starfish sperm motility. Develop. Growth Differ. 29, 563-569.

O'Dea, R.F., Haddox, M.K. \& Goldberg, N.D. (1970) Kinetic analysis of a soluble rat brain cyclic nucleotide phosphodiesterase. Fedn Proc. Fedn Am. Soc. exp. Biol. 29, 473.

Robertson, L., Wolf, D.P. \& Tash, J.S. (1988) Temporal changes in motility parameters related to acrosomal status and identification and characterization of populations of hyperactivated human sperm. Biol. Reprod. 39, 797-805.

Rogers, B.J. \& Yanagimachi, R. (1975) Retardation of guinea pig sperm acrosome reaction by glucose: the possible importance of pyruvate and lactate metabolism in capacitation and the acrosome reaction. Biol. Reprod. 13, 568-575.

Rogers, B.J. (1978) Mammalian sperm capacitation and fertilization in vitro: a critique of methodology. Gamete Res. 1, 165-223.

Rogers, B.J., Chang, L. \& Yanagimachi, R. (1979) Glucose effect on respiration: possible mechanism for capacitation in guinea pig spermatozoa. J. exp. Zool. 207, 107-112. 
Sheppard, H., Wiggan, G. \& Tsien, W.H. (1972) Structure-activity relationships for inhibitors of phosphodiesterase from erythrocytes and other tissues. $A d v$. Cyclic Nucleotide Res. 1, 103-112.

Suter, D., Chow, P.Y.W. \& Martin, I.C.A. (1979) Maintenance of motility in human spermatozoa by energy derived through oxidative phosphorylation and addition of albumin. Biol. Reprod. 20, 505-510.

Tash, J.S. \& Means, A.R. (1983) Cyclic adenosine $3^{\prime}, 5^{\prime}-$ monophosphate, calcium and protein phosphorylation in flagellar motility. Biol. Reprod. 28, 75-104.

Tash, J.S., Hidaka, H. \& Means, A.R. (1986) Axokinin phosphorylation by cAMP-dependent protein kinase is sufficient for activation of sperm flagellar motility. J. cell Biol. 103, 649-655.

Triner, L., Vulliemoz, Y., Schwartz, I. \& Nahas, G.G. (1970) Cyclic phosphodiesterase activity and the action of papaverine. Biochem. Biophys. Res. Commun. 40, 64-69.
Vigdahl, R.L., Mongin, J. Jr. \& Marquis, N.R. (1971) Platelet aggregation IV. Platelet phosphodiesterase and its inhibition by vasodilators. Biochem. Biophys. Res. Commun. 42, 1088-1084.

Vijayaraghavan, S. \& Hoskins, D.D. (1986) Regulation of bovine sperm motility and cyclic adenosine $3^{\prime}, 5^{\prime}-$ monophosphate by adenosine and its analogues. Biol. Reprod. 34, 468-477.

Weiss, B. (1975) Differential activation and inhibition of the multiple forms of cyclic nucleotide phosphodiesterase. Adv. Cyclic Nucleotide Res. 5, 195-211.

Wulff, K. \& Döppen, W. (1985) Luminometric methods. In Methods of Enzymatic Analysis, pp. 357-364. Eds H. V. Bergmeyer, J. Bergmeyer \& M. Graßl. VCH Publishers, FRG.

Received 9 July 1990 